\title{
Green energy recovery by blending treated biogas into town gas pipeline networks
}

\author{
Mario Ho Tak Cheung* \\ The Hong Kong and China Gas Company Limited, Hong Kong, People's Republic of China
}

\begin{abstract}
Biogas can be converted into treated biogas or synthetic natural gas, which can be blended into town gas pipeline network at a designed mixing ratio. Specific gravity and calorific value of biogas are adjusted to satisfy gas safety and quality standard. Carbon dioxide pressure swing adsorption is selected and applied for specific gravity reduction and calorific value enrichment. $95 \%$ nitrogen, defined according to the flammability plot, is mixed with biogas for tuning the calorific value at the end of the process end. Gas interchangeability of the gas mixture of treated biogas and town gas was predicted by using maximum combustion potential (MCP) chart and their maximum mixing ratio for safe use was indicated. Gas interchangeability of the gas mixture was tested to confirm the prediction. The South East New Territories Processing Facilities were designed and built according to the above principle, and has been in operation to convert biogas into synthetic natural gas successfully since 2017 .
\end{abstract}

KEYWORDS Gas and energy; biogas recovery; calorific value; specific gravity, gas interchangeability

CONTACT Mario Ho Tak Cheung mario.cheung@towngas.com

Received 27 March 2020

\section{Introduction}

Biogas, produced by anaerobic digestion of organic material in landfills or anaerobic digesters, mainly consists of methane and carbon dioxide with a trace amount of impurities such as hydrogen sulphide, moisture and volatile organic compounds (VOCs). Methane has a calorific value (CV) of $37.71 \mathrm{MJ} / \mathrm{m}^{3}$ measured at $15^{\circ} \mathrm{C}$ and atmospheric pressure (Zabetakis, 1965). It combusts in the presence of oxygen to provide heat energy and can fuel gas engine for combined heat and power (CHP) generation. This green energy is worth recovering instead of simply burnt off. So normally, those landfills or anaerobic digesters utilise part of the biogas for internal heat and power consumption while flaring the surplus biogas when there is no other use. This is very common in the old days, especially in landfills.

Flaring biogas causes environmental impact as it emits greenhouse gases to the atmosphere. Releasing biogas directly to the atmosphere would be even worse as methane has a global warming potential (GWP) 21 times that of carbon dioxide (BBC Weather Centre, 2014).

There are a number of existing methods to recover surplus biogas. The three basic ways to use biogas are electricity generation, vehicle fuel and production of heat and steam.

Electricity generation can be done by fuelling the internal combustion engine, gas turbine engine and micro turbine engine, which convert the surplus biogas into electricity and transmit it to the power grid. However, this is not the best option in view of energy efficiency. The typical electricity generation and transmission efficiency is around $40 \%$ while the efficiency for biogas treatment and transmission can be up to $90 \%$ or more ( $\mathrm{Li}$ and Khanal, 2016). Hence, utilising biogas as fuel can boost up energy recovery. For vehicle fuel, biogas can be upgraded to natural gas quality with methane content greater than $90 \%$ and a low level of impurities. However, in places like Hong Kong where there is no natural gas vehicle in the market, the application is limited.

In Hong Kong, Shuen Wan (SW) Landfill and North East New Territories (NENT) Landfill are two examples where biogas is treated and delivered for the purpose of producing heat (Towngas, 2020).

In 1999, Towngas constructed Hong Kong's first landfill gas utilisation plant at the SW Landfill with over HK\$10 million. A simple treatment unit was installed with gas compression and dewatering process carried out prior to delivering the biogas into a $1.3-\mathrm{km}$ underground pipeline to Tai Po Gas Production Plant as fuel.

In 2007, Towngas and landfill operator invested a total of HK\$250 million for the construction of Landfill Gas Treatment Unit at NENT Landfill and a 19-km underground pipeline. Part of the carbon dioxide in biogas is removed for enriching its methane content to $80 \%$ or more. The product gas, named as substitute natural gas, is transmitted to Tai Po Gas Production Plant as fuel. Besides, part of the gas is supplied to fuel the CHP system at the Alice Ho Miu Ling Nethersole Hospital. The project cuts the emission of carbon dioxide by 135,000 tonnes annually (Towngas, 2020).

In fact, it is not an easy task to find nearby end-users of treated biogas. Supplying biogas to distant users may not be economical as the investment of underground pipeline installation could offset the revenues obtained from the sales of the biogas.

Injecting biogas or treated biogas into transmission pipeline can cater for the issue of limited end-users nearby. As mentioned, biogas can be upgraded into natural gas 
quality. However, the coverage of natural gas network in some places such as Hong Kong is not comprehensive. If blending treated biogas into town gas pipeline networks is feasible, biogas utilisation would be easier and much more flexible regardless of the geographical limit as town gas pipeline networks cover most parts of Hong Kong. However, since town gas and biogas are two different gas mixtures with different compositions and physical properties, detailed quality control and choices of processing for such biogas treatment are very important.

\section{Biogas and towngas}

Town gas is a clean, safe and reliable gaseous fuel produced from naphtha and natural gas in Tai Po and Ma Tau Kok Gas Production Plants in Hong Kong (Towngas, 2020). With about half the density of air, town gas rises and dissipates in the air if leakage occurs. A special odour, named as tetrahydrothiophene, is added to town gas so that it can be detected easily. It mainly consists of hydrogen which biogas does not have. Hence, the composition and physical properities between biogas and town gas are quite different and the the two fuels are not interchangeable.

Table 1. Compositions and physical properties of town gas (TG) and biogas at dry basis.

\begin{tabular}{ccc}
\hline & TG & Biogas \\
\hline $\mathrm{CO}_{2}$ & $16.3 \%-19.9 \%$ & $20-55 \%$ \\
\hline $\mathrm{CO}$ & $1.0 \%-3.1 \%$ & $/$ \\
\hline $\mathrm{CH}_{4}$ & $28.2 \%-30.7 \%$ & $40-65 \%$ \\
\hline $\mathrm{H}_{2}$ & $46.3 \%-51.8 \%$ & $/$ \\
\hline $\mathrm{N}_{2} \& \mathrm{O}_{2}$ & $0 \%-3.3 \%$ & $0-15 \%$ \\
\hline $\begin{array}{c}\text { Calorific Value } \\
(\mathrm{CV})\end{array}$ & $17.27 \mathrm{MJ} / \mathrm{m}^{3}$ & $\begin{array}{c}15.08 \mathrm{MJ} / \mathrm{m}^{3}- \\
24.51 \mathrm{MJ} / \mathrm{m}^{3}\end{array}$ \\
\hline $\begin{array}{c}\text { Specific Gravity } \\
(\mathrm{SG})\end{array}$ & 0.52 & $0.9-1.15$ \\
\hline $\begin{array}{c}\text { Wobbe Index } \\
(\mathrm{WI})^{1}\end{array}$ & $24 \mathrm{MJ} / \mathrm{m}^{3}$ & $14 \mathrm{MJ} / \mathrm{m}^{3}-$ \\
\hline
\end{tabular}

${ }^{1} \mathrm{CV}$ and $\mathrm{WI}$ are measured at $15^{\circ} \mathrm{C}$ and atmospheric pressure.

Specific gravity (SG) would be considered as one of the safety parameters for gas distribution systems. It is the density ratio of a substance to a reference. For gas, air is taken as the reference, so its SG is 1. A particular gas with a SG greater than 1 means the gas is heavier than air and could easily accumulate on the ground level rather than dissipate in case of gas leakage. If the concentration of accumulated flammable gas reaches the lower explosive limit (LEL), there will be a risk of fire. Therefore, the SG should be controlled below 0.95 to minimise gas accumulation in case of gas leakage.
$\mathrm{CV}$ or heating value is the amount of energy released from complete combustion of fuel. The $\mathrm{CV}$ of town gas is $17.27 \mathrm{MJ} / \mathrm{m}^{3}$. For biogas, its $\mathrm{CV}$ fluctuates depending on the substrate digested and the condition in landfills or anaerobic digesters. It shall be adjusted to the same CV as town gas prior to injection into the grid.

Gas interchangeability is the ability to substitute one gaseous fuel for another without impacting combustion performance. In Hong Kong gas appliances, maximum combustion potential (MCP) and Wobbe Index (WI) are the key parameters to determine the gas interchangeability. A maximum mixing ratio between town gas and biogas shall be identified to overcome the significant differences in the physical properties between the two gas fuels and achieve an interchangeable gas.

\section{SG control}

SG is related to the gas safety at underground pipeline systems and shall be controlled below 0.95 such that it is lighter than air. SG is the density ratio of the gas in interest to air (Engineering ToolBox, 2003).

$$
S G_{c}=\frac{\rho_{s}}{\rho_{\text {air }}}
$$

, where $S G_{c}$ is the $\mathrm{SG}$ of a pure component, $\rho_{S}$ is the density of sample, and $\rho_{\text {air }}$ is the density of air.

Table 2. SG of components.

\begin{tabular}{|cc|}
\hline & $\mathrm{SG}$ \\
$\mathrm{H}_{2}$ & 0.0696 \\
$\mathrm{CO}$ & 0.9617 \\
$\mathrm{CO}_{2}$ & 1.5195 \\
$\mathrm{CH}_{4}$ & 0.5539 \\
$\mathrm{O}_{2}$ & 1.1043 \\
$\mathrm{~N}_{2}$ & 0.9668 \\
\hline
\end{tabular}

The calculation of the SG of a gas mixture is given by:

$$
S G_{m}=\sum\left(S G_{c} \times V_{c}\right)
$$

, where $S G_{m}$ is the SG of gas mixture, $S G_{c}$ is the SG of a pure component, and $V_{c}$ is the volume percentage of a component in the gas.

Biogas has an SG in the range of 0.9-1.15. In order to reduce the $\mathrm{SG}$ of a gas, separating carbon dioxide out from methane can be carried out as carbon dioxide has an SG of 1.52. There are a number of proven and mature technologies such as pressure swing adsorption (PSA), 
membrane separation and cryogenic separation to achieve carbon dioxide separation.

PSA works with adsorbent with pore structure to separate gases with different boiling points (Rousseau, 1987). For carbon dioxide and methane separation, silica gel, which is an amorphous and porous form of silicon dioxide (silica), is a typical adsorbent known as a type of desiccant. Carbon dioxide molecules have a higher boiling point than methane, which results in a stronger van der Waals force between the adsorbent and a high adsorption rate. Meanwhile, part of the adsorbing molecules may receive a "kick-off' energy by the jiggle atoms nearby, also known as the process called desorption. Under high pressure, adsorption rate is initially faster than desorption as molecules hit on the adsorbent surface more frequently, and vice versa. The adsorbent is saturated when the adsorption rate and desorption rate are balanced. Regeneration is then carried out by releasing the adsorber pressure to the ambient. Then, the adsorbent can be used for the next cycle. The desorbed gas, which is not pure carbon dioxide and contains a portion of methane, goes to flare prior to discharge, in order to minimise the greenhouse effect caused by methane.
Membrane separation requires a bundle of hollow fibres with a high surface area to volume ratio. Gases with a higher diffusion rate and smaller molecular size penetrate the membrane faster than gases of lower diffusion and larger molecular size. Methane is the retentate having a lower permeation velocity than the carbon dioxide (the permeate).

Cryogenic separation can be applied for high purity nitrogen generation, but both investment and operation costs are much higher than PSA and membrane separation systems. It works by liquefying carbon dioxide at the combination of high pressure and low temperature, which requires a significant energy input and does not match with energy recovery purpose.

Both membrane separation and PSA technologies can work at ambient temperature and require hydrogen sulphide removal, dewatering and oil removal of biogas in order to protect the separation unit. PSA works at a lower operating pressure ( $\sim 500 \mathrm{kPag}-700 \mathrm{kPag})$ and adsorbents have a longer lifespan than hollow fibre membranes. PSA is chosen as the preferred for this case. It is worth noting that technology selection shall be considered on a case-bycase basis depending on actual conditions and requirement such as purity, equipment space, power consumption and discharge pressure etc.

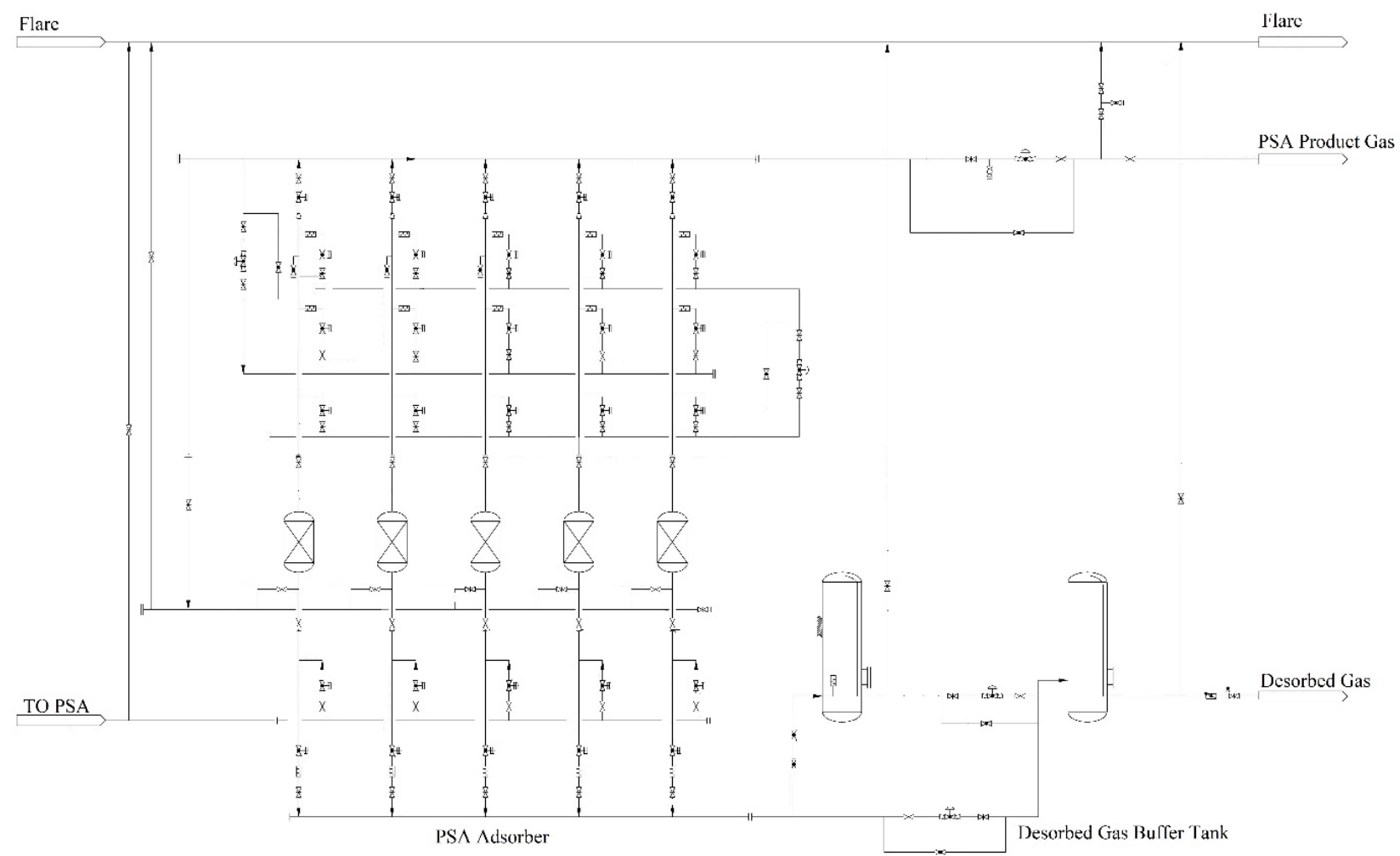

Figure 1. Carbon dioxide pressure swing adsorption general schematic. 


\section{4. $C V$ control}

$\mathrm{CV}$ refers to the energy output from complete combustion and can be estimated by the equation below (Zabetakis, 1965).

$$
C V_{m}=\sum\left(C V_{c} \times V_{c}\right)
$$

, where $C V_{m}$ is the $\mathrm{CV}$ of the gas mixture, $C V_{c}$ is the $\mathrm{CV}$ of a pure component, and $V_{c}$ is the volume percentage of a component in the gas.

Table 3. CV of major flammable components. ${ }^{2}$

\begin{tabular}{|c|c|}
\hline Component & Gross CV \\
\hline $\mathrm{H}_{2}$ & 12.102 \\
\hline $\mathrm{CO}$ & 11.96 \\
\hline $\mathrm{CH}_{4}$ & 37.71 \\
\hline
\end{tabular}

${ }^{2}$ Gross $\mathrm{CV}$ reflects the value at $15{ }^{\circ} \mathrm{C}$ and atmospheric pressure.
$\mathrm{CV}$ of biogas varies above or below $17.27 \mathrm{MJ} / \mathrm{m}^{3}$ depending on the anaerobic condition. Different processes should be applied depending on whether the CV of the biogas is higher or lower than the required value. In cases of a high CV, dilution with non-flammable gas can be applied to lower the CV. Non-flammable components do not have heating values, and one common flammable gas is air, which is everywhere and can be readily obtained. Blending with air products is an easy and economical way to achieve the goal. For other non-flammable gases, the blending cost would be relatively expensive as the gas consumption rate could be significant in the process.

Air consists mainly of nitrogen and oxygen with a small amount of argon, carbon dioxide and other gases, the $\mathrm{CV}$ of which is negligible. However, when mixing flammable gases with oxygen, explosion limits should always be checked and identified to avoid creation of explosive mixtures. The maximum concentration of a gas or vapour that can burn in the air is defined as the upper explosive limit (UEL) (Hattwig and Steen, 2004). Above this level, the mixture is too "rich" to burn. The range between the LEL and UEL is classified as the combustible zone, in which the concentration of the material in the air will burn or explode in the presence of an ignition source.

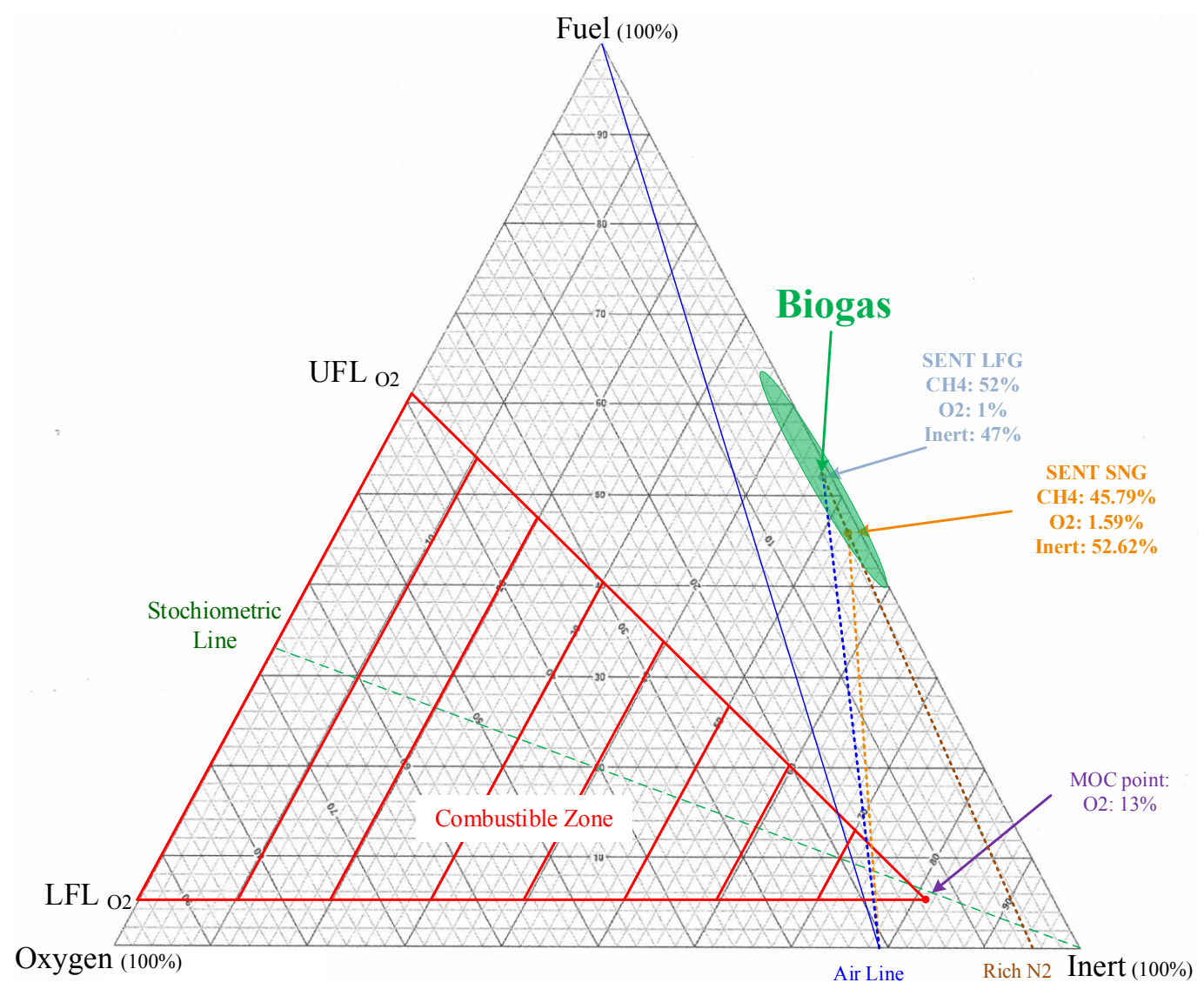

Figure 2. Flammability plot of biogas. 


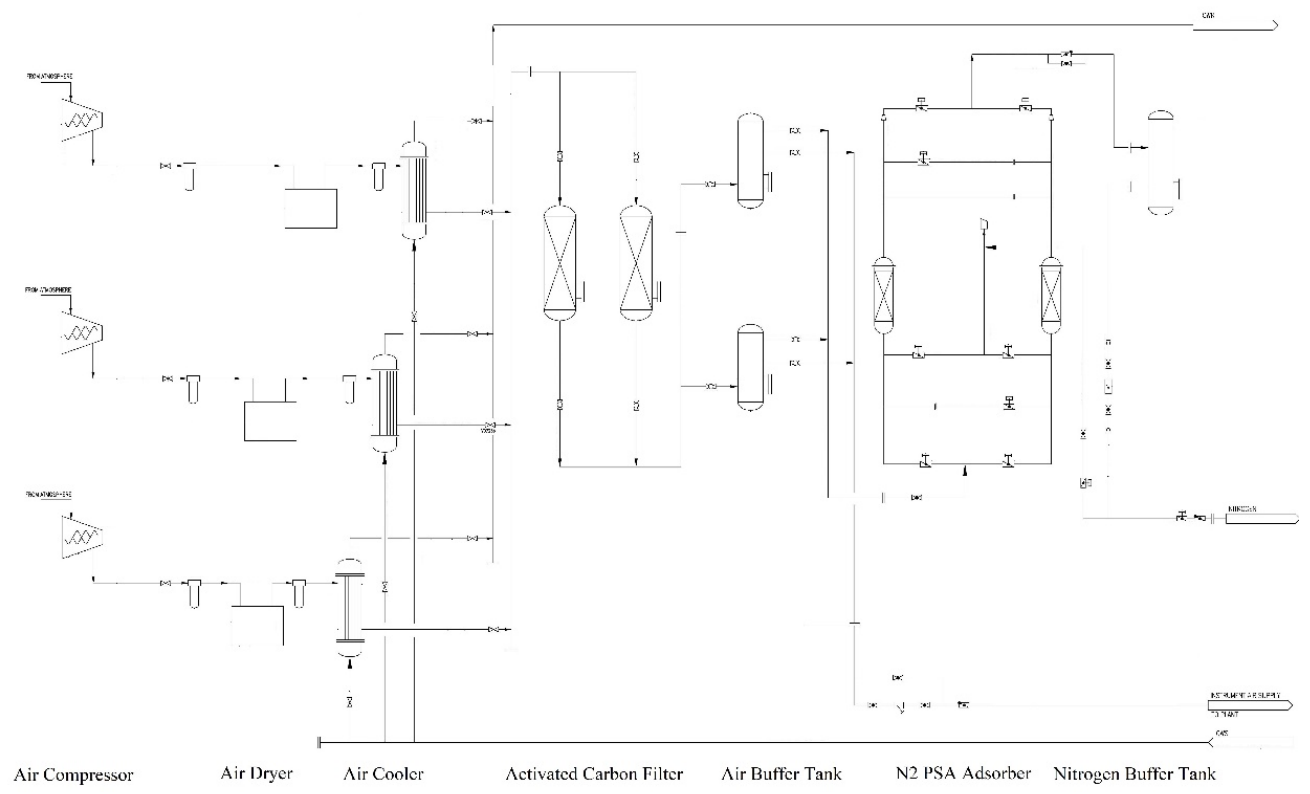

Figure 3. Nitrogen pressure swing adsorption general schematic.

Typically, biogas is outside the combustible zone and is therefore not combustible. However, when biogas is mixed with air to lower the $\mathrm{CV}$, the gas mixture will follow the air line. Theoretically, the gas mixture is still located far away from the combustible zone as the mixing ratio to air is around 1 in extreme cases ${ }^{3}$, and the mixture is located at the centre of the line between biogas and air.

However, operation may not always be as stable as designed and abnormal situations shall always be considered. Gas blending is achieved by means of a control valve through regulating the injection flow rate of nonflammable gas in response to the feedback signal from an online $\mathrm{CV}$ analyser. If there is a failure of valve positioner or other instrument fault, they result in excess air injection to the biogas causing the gas mixture to fall inside the combustible zone. Any spark or ignition source could ignite the gas mixture inside the pipeline system and cause fires or even explosions.

95\% nitrogen with $5 \%$ oxygen (rich nitrogen) would be used for reducing the $\mathrm{CV}$ of biogas. The nitrogen-rich gas can be produced from air separation processes such as PSA, membrane separation and cryogenic process. These processes have certain differences in design and operation such as operation pressure, adsorbents and regeneration cycle times and number of adsorbers. The typical adsorbent for oxygen adsorption is carbon molecular sieve. Oxygen molecules are slightly smaller than nitrogen molecules, and diffuse faster into the inner surface of the pore structure. In line with the argument mentioned in Section 3, PSA is preferred.
In case of low $\mathrm{CV}$, the strategy is simply reversed. Instead of using gas diluting, non-flammable gas such as carbon dioxide is separated from the biogas. Reducing the carbon dioxide content in biogas can raise the CV. As a result, a single unit of carbon dioxide PSA can achieve both purposes of reducing $\mathrm{SG}$ and $\mathrm{CV}$.

\section{Gas interchangeability}

After going through the process of SG control and CV control, the treated biogas shall be checked for its ability to burn properly in the gas appliance as it is designed to blend with town gas. In Hong Kong, the MCP chart was prepared for checking the gas interchangeability.

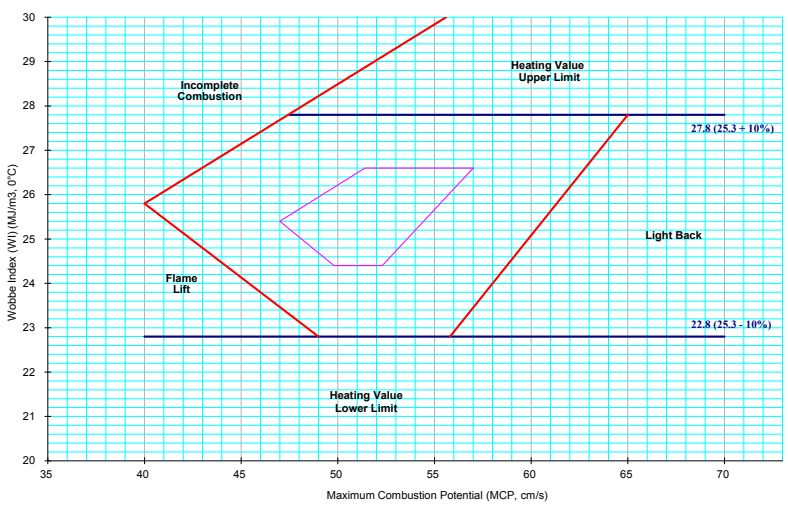

Figure 4. MCP chart of Hong Kong's gas appliances.

${ }^{3}$ An extreme case is defined as biogas having $100 \%$ methane with a $\mathrm{CV}$ of $37.71 \mathrm{MJ} / \mathrm{m}^{3}$. Mixing ratio between the gas to dilution gas is $118 \%$ to achieve a mixed gas with $\mathrm{CV}$ of $17.27 \mathrm{MJ} / \mathrm{m}^{3}$. 
Table 4. Data for MCP calculation.

\begin{tabular}{|c|c|c|c|c|c|c|c|c|c|c|}
\hline Function & $\mathrm{H}_{2}$ & $\mathrm{CO}$ & $\mathrm{CH}_{4}$ & $\mathrm{C}_{2} \mathrm{H}_{6}$ & $\mathrm{C}_{2} \mathrm{H}_{4}$ & $\mathrm{C}_{3} \mathrm{H}_{8}$ & $\mathrm{C}_{3} \mathrm{H}_{6}$ & $\mathrm{C}_{4} \mathrm{H}_{10}$ & $\mathrm{C}_{4} \mathrm{H}_{8}$ & $\mathrm{C}_{\mathrm{m}} \mathrm{H}_{\mathrm{n}}$ \\
\hline$u_{1}$ & 282 & 100 & 36 & 41 & 66 & 41 & 47 & 38 & 47 & 40 \\
\hline$f_{1}$ & 1 & 0.781 & 8.72 & 16.6 & 11 & 24.6 & 21.8 & 32.7 & 28.5 & 38.3 \\
\hline$\alpha_{1}$ & 1.33 & 1 & 2 & 4.55 & 4 & 4.55 & 4.55 & 5.56 & 4.55 & 4.55 \\
\hline
\end{tabular}

The MCP chart shown in Figure 4 was drawn by Towngas' Japanese suppliers after years of comprehensive appliances testing, which does not solely rely on theoretical calculations. The appliance test was designed for pure naphtha mode with acceptable testing range of $\pm 10 \%$ heating value. The WI of town gas produced by pure naphtha is $25.3 \mathrm{MJ} / \mathrm{m}^{3}$ at normal condition, so the upper and lower limits of the chart are $25.3 \pm 10 \% \mathrm{MJ} / \mathrm{m}^{3}$.

If the gas physical properties fall into the centre small polygon of the MCP Chart, the gas is perfectly interchangeable. Being inside the large polygon basically means safe and interchangeable, but one should be prudent of the flame properties which may not be acceptable to some appliances. When falling outside the boundary of the large polygon, incomplete combustion, flame lift and light back may happen depending on the gas's physical properties.

Gases of similar WI will give similar heat input as the gas flow through a burner orifice is inversely proportional to the square root of the density of the gas. WI is expressed in $\mathrm{MJ} / \mathrm{Nm}^{3}$ and can be calculated by the Equation below (GB 13611, 2018):

$$
W I=\frac{C V}{\sqrt{S G}}
$$

, where $W I$ is the WI of gas mixture.

$\mathrm{MCP}$ is one of the indices reflecting the speed of the flame front travels back. When the flame speed is greater than the ejection speed of the gas and air mixture out from the burner, it results in light-back. On the contrary, flame lift happens. As flame speed of a gas is difficult to measure, empirical formula is used for the prediction. MCP can be calculated by the empirical formulae below:

$$
\begin{aligned}
& u=\frac{\sum\left(u_{1} f_{1} A_{1}\right)}{\sum\left(u_{1} A_{1}\right)}(1-k) \\
& k=\frac{\sum A_{1}}{\sum\left(\alpha_{1} A_{1}\right)}\left[\frac{2.5 \mathrm{CO}_{2}+N_{2}-3.770_{2}}{100-4.770_{2}}+\left(\frac{N_{2}-3.770_{2}}{100-4.770_{2}}\right)^{2}\right]
\end{aligned}
$$

, where $u$ is the MCP $(\mathrm{cm} / \mathrm{s}) ; u_{1}$ is the MCP of each component $(\mathrm{cm} / \mathrm{s}) ; f_{1}$ is the coefficient of each combustible component (see Table 4); $\alpha_{1}$ is the coefficient of each combustible component (see Table 4); $A_{1}$ is the volume percentage of each combustible component in gas ( $\%) ; \mathrm{CO}_{2}$ is the volume percentage of carbon dioxide in gas (\%); $\mathrm{N}_{2}$ is the volume percentage of nitrogen in gas (\%); and $\mathrm{O}_{2}$ is the volume percentage of oxygen in gas $(\%)$.

For the treated biogas, the CV and SG are controlled at $17.27 \mathrm{MJ} / \mathrm{m}^{3}$ and 0.95 respectively. The respective WI and $\mathrm{MCP}$ are around $17.7 \mathrm{MJ} / \mathrm{Nm}^{3}$ and $19 \mathrm{~cm} / \mathrm{s}$, which are far away from the large polygon, and probably will result in flame lift when used as fuel for Hong Kong gas appliances. Treated biogas is not interchangeable because of the absence of hydrogen.

Hence, there is a maximum mixing ratio between the treated biogas and town gas for achieving interchangeability, which can be figured out by plotting gaseous with different mixing ratios into the MCP chart. A maximum mixing ratio was designed as $8 \%$ for a specific landfill gas. This value is not generic and may vary from case to case.

A gas appliances test was further carried out to verify the interchangeability calculation of the mixed gas of treated biogas and town gas. Mixed Gas I and Mixed Gas II were tailor-made for the test with mixing ratios of $6 \%$ and $10 \%$ ( $\pm 2 \%$ of $8 \%$ maximum mixing ratio). The composition and physical properties are presented in Table 5.

Table 5. Gas compositions and physical properties of Mixed Gases I \& II.

\begin{tabular}{ccc}
\hline & $\begin{array}{c}\text { Mixed Gas I } \\
\text { Mixing ratio 6\%) }\end{array}$ & $\begin{array}{c}\text { Mixed Gas II } \\
\text { (Mixing ratio 10\%) }\end{array}$ \\
\hline $\mathrm{CO}_{2}$ & $18.2 \%$ & $18.6 \%$ \\
\hline $\mathrm{CO}$ & $1.2 \%$ & $1.1 \%$ \\
\hline $\mathrm{CH}_{4}$ & $30.1 \%$ & $45.9 \%$ \\
\hline $\mathrm{H}_{2}$ & $47.6 \%$ & $30.7 \%$ \\
\hline $\mathrm{N}_{2}$ & $2.4 \%$ & $3.0 \%$ \\
\hline $\mathrm{O}_{2}$ & $0.5 \%$ & $0.6 \%$ \\
\hline $\begin{array}{c}\text { Calorific Value } \\
(\mathrm{CV})\end{array}$ & $17.27 \mathrm{MJ} / \mathrm{m}^{3}$ & $17.27 \mathrm{MJ} / \mathrm{m}^{3}$ \\
\hline $\begin{array}{c}\text { Specific Gravity } \\
(\mathrm{SG})\end{array}$ & 0.518 & 0.534 \\
\hline $\begin{array}{c}\text { Wobbe Index } \\
(\text { WI })\end{array}$ & $24.0 \mathrm{MJ} / \mathrm{m}^{3}$ & $23.6 \mathrm{MJ} / \mathrm{m}^{3}$ \\
\hline
\end{tabular}

One domestic appliance (TGC Hotplate R22) and one commercial stockpot were selected as the testing appliances for the gases. 
(a) TGC Hotplate R22
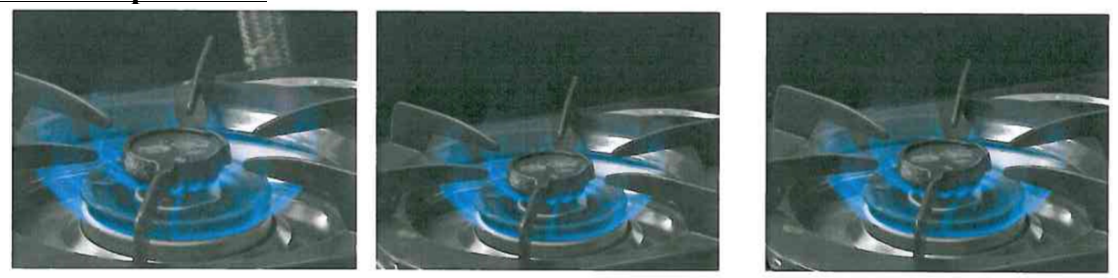

100\% Town GasMixed Gas IMixed Gas II

(b) Commercial stockpot
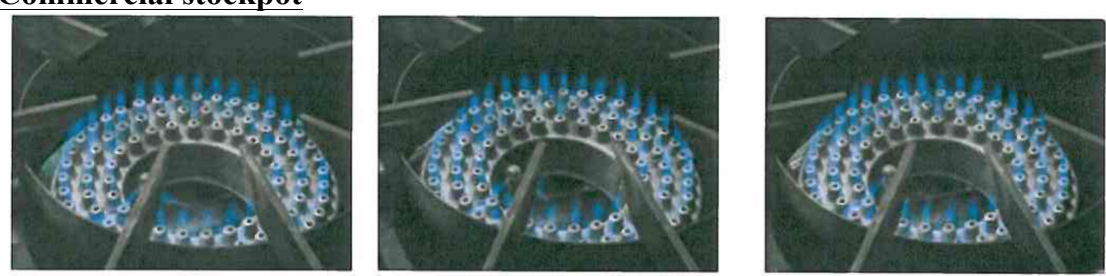

100\% Town GasMixed Gas IMixed Gas II

Figure 5. Photo captured during gas appliance test.

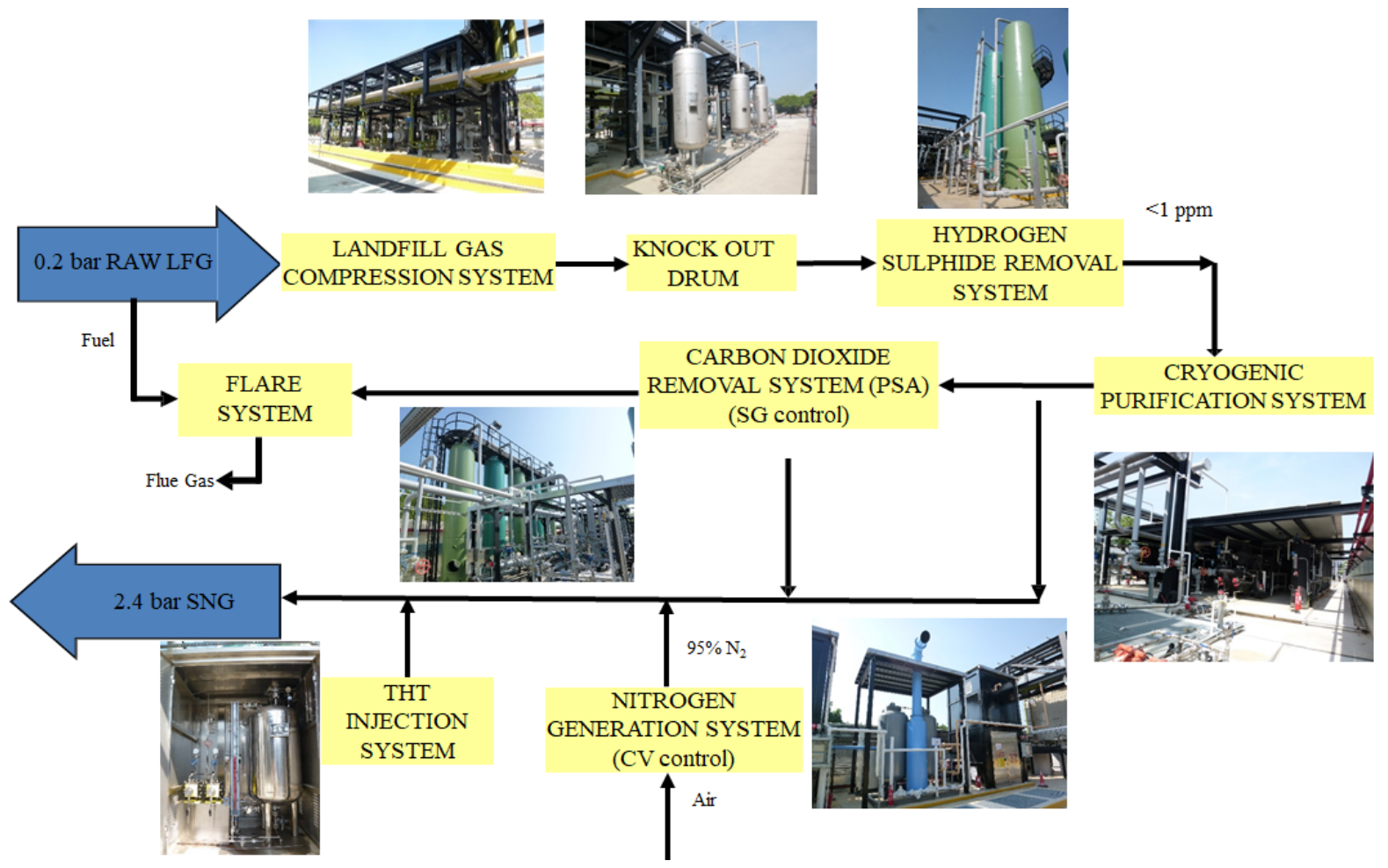

Figure 6. Process flow diagram of South East New Territories Processing Facilities. 
As shown in Figure 5, the appearance of the flame of all appliances is very similar without any observable differences. The flame condition is stable and free from light-back, flame lift and yellow tripping for the whole operating range from full rate to reduced rate. The gas is undergoing complete combustion with a blue flame that sits properly on the burner. This represents that, practically, mixing $10 \%$ landfill gas into town gas is interchangeable to town gas with negligible effect to the flame condition of the gas mixture.

\section{Implementation}

In 2017, Towngas designed and built Processing Facilities at Tseung Kwan O South East New Territories (SENT) Landfill to treat biogas with an investment of approximately HK $\$ 350$ million. The treated biogas, called synthetic natural gas (SNG), is delivered to the off take station in Tseng Lan Shue through a $12-\mathrm{km}$ pipeline and blended into town gas through the ejector. The design treatment capacity is $8,000 \mathrm{~m}^{3}$ of biogas/hour.

Apart from applying the $\mathrm{SG}$ and $\mathrm{CV}$ control mentioned above, the facilities adopted advanced technology including desulphurisation, cryogenic purification system for impurities removal and adding of the odorant tetrahydrothiophene (THT), same as town gas treatment.

In a carbon dioxide removal system, the methane content at the outlet is up to $60 \%$ or above while $45.8 \%$ methane content is equivalent to $17.27 \mathrm{MJ} / \mathrm{m}^{3}$. Hence, part of the biogas bypasses the PSA system instead of entirely entering the unit. The bypass gas and PSA outlet gas combine afterwards at the exit. This reduces the capacity of the PSA system, space requirement, and its investment cost.

The PSA process contains five adsorption vessels and operates in a "5-1-2/P" mode (i.e. 5 vessels configuration, 1 vessel in adsorption, 2-step depressurisation/repressurisation, regeneration by purging). In this mode, one vessel is in the carbon dioxide adsorption mode. Each vessel will go through the following steps one-byone at different time intervals and stages of the process, which are adsorption, 2-step concurrent depressurisation for equalisation, providing purging, countercurrent depressurisation, purging, 2-step re-pressurisation for equalisation and final pressurisation.

PSA operates in a cycle with different stages for regeneration; changes in the amount of the adsorbed carbon dioxide and the discharged methane content will result in an unstable CV. To deal with gas quality issue, the CV of the combined gas is first controlled at $19 \mathrm{MJ} / \mathrm{m}^{3}$ roughly and then fine-tuned by blending nitrogen gas, which has an SG very close to 1 and would only slightly increase the blended gas's SG. To address this, the upstream SG is recommended to be adjusted to 0.93 or below.

Two sets of air compressor and post-treatment system (including refrigeration-type air dryers, pre-filters and postfilters) are installed to supply sufficient air to the nitrogen generation system. The compressed air enters a carbon filter and two air buffer tanks before undergoing PSA adsorption. Two PSA vessels with adsorbent works alternately to produce the required $95 \%$ nitrogen. The nitrogen produced is stored in a buffer tank to maintain the nitrogen supply and cater for the fluctuation of nitrogen demand with time.

During testing and commissioning, another gas appliances test was performed at the off take station to further confirm the gas interchangeability. The testing result was similar to the previous satisfactory result. The operating mixing ratio is well controlled below $8 \%$ by the mechanical design of the ejector.

SNG reduces the production of town gas in Tai Po Gas Production Plant and saves the raw material consumption. Producing a cubicmetre of SNG saves around $0.36 \mathrm{~kg}$ naphtha, equivalent to $1.11 \mathrm{~kg}$ carbon dioxide emission. ${ }^{4}$

As one of the largest energy conservation and emission reduction environmental projects in Hong Kong, this wasteto-energy project is expected to reduce the emission of carbon dioxide by 56,000 tonnes per year, equivalent to the absorption of 2.4 million tree seedlings per year.

\section{Alternative method}

It requires at least $100,000 \mathrm{~m}^{3} /$ hour town gas for achieving gas interchangeability of $8,000 \mathrm{~m}^{3} /$ hour treated biogas based on the designed $8 \%$ maximum mixing ratio. The maximum supply capacity of the Tai Po Plant and Ma Tau Kok Plant is around 500,000 $\mathrm{m}^{3}$ /hour in 2020 (Towngas, 2020). Searching for a blending point with sufficient town gas flow rate is a great challenge when more treated biogas is recovered by injecting into the town gas pipeline network.

There is a method to convert biogas into a gas complying with town gas standard through steam reforming on the nickel-based catalyst and water gas shift reaction (Milbrandt, 2014). These hydrogen-generating processes involve chemical reactions and high-temperature processes, which would boost both the investment cost and operation cost by double or more. The plant startup time would be longer for pre-heating the reforming tube to a high temperature (e.g. $700^{\circ} \mathrm{C}$ ). Additional high-pressure steam is required as the reactant of steam reforming reaction. Part of the biogas is consumed for heating purposes, which reduces the recovery rate. Additional utilities, process protection

\footnotetext{
${ }^{4}$ Assuming the $\mathrm{CV}$ and carbon to hydrogen ratio $(\mathrm{C} / \mathrm{H})$ of naphtha is $48 \mathrm{MJ} / \mathrm{kg}$ and 5.3 , respectively.
} 
devices, and shift manpower become complex and demanding. The revenue from the biogas recovery comes from the naphtha saving at Tai Po Plant. When the quantity of biogas and oil price level are at a high level, it may still be financially attractive to operate.

In Hong Kong, Environmental Protection Department, HKSAR intends to use organic waste in anaerobic digestion plants called the organic resource recovery centers (ORRCs) for solving waste disposal problems and recovering wasted energy (Environmental Protection Department, 2020). The first phase of ORRCs, ORRC (Phase 1), is located at Siu Ho Wan in North Lantau for treating source-separated organic waste generated from the commercial and industrial sectors at a capacity of 200 tonnes per day. The facility has been in full operation since 2018. The second phase of ORRCs, ORRC (Phase 2), is located at Sha Ling in the North District, which comprises a daily treatment capacity of 300 tonnes. The predicted surplus biogas generation, excluding the gas for internal use, is around several thousand cubicmeter per hour, which matches for smallscale investments and it is not worth building a complex town gas production plant there for biogas recovery. Meanwhile, less organic waste will be dumped into landfills year-by-year, reducing the landfill gas generation rate.

As a result, small-scale treatment plants, which work with simple design and normal operating temperatures without chemical reaction and most importantly, with a low investment cost, are more suitable for biogas recovery. The energy recovery rate for blending treated biogas into town gas pipeline network is higher than converting treated biogas into town gas. It makes green energy recovery projects more financially feasible.

\section{Conclusion}

Through the process of SG and CV control, biogas recovery can be implemented by converting biogas into treated biogas or synthetic natural gas and inject it into town gas pipeline network at a designed mixing ratio. SG control can be done by carbon dioxide pressure swing adsorption, which can increase the $\mathrm{CV}$ of the gas. The final $\mathrm{CV}$ adjustment can be made by mixing biogas with $95 \%$ nitrogen, defined according to the flammability plot. By using the MCP chart, gas interchangeability of the gas mixture of treated biogas and town gas is indicated with the mixing ratio for safe use, which is also verified by gas appliances tests. An example is seen in the SENT Processing Facilities, which was designed and built according to the above principle and has been in operation to convert biogas into synthetic natural gas successfully since 2017.

The process adopts simple design with low investment cost, and operates at normal operating temperature without chemical reaction involved. It can serve as an option for biogas recovery in a flexible way.

\section{Acknowledgments}

The author would like to express his deep appreciation and indebtedness to The Hong Kong and China Gas Company (Towngas) for giving the author an opportunity to explore deeper in engineering field.

Ir Simon Ngo SH, Ir Stephen Chan KT, Ir Ian Tang SK and Ir Dr William Ip N B for their endless support, professional guidance and experience sharing.

Mr Vincent Ng W P, Mr Jason Li K C, Mr Tse S F, shift engineers and shift technicians in SENT Processing Facilities for constructive recommendations and assistance.

\section{Notes on Contributor}

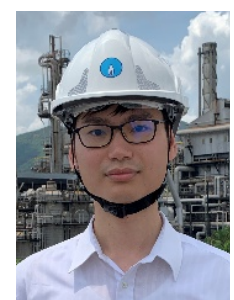

Mr Mario Ho Tak Cheung is an engineer with The Hong Kong and China Gas Company Limited in Hong Kong. He began working in a landfill gas utilisation project called SENT, which involved the project management of design, supply, delivery, installation, testing and commissioning of the processing facilities. He received his M.Sc. degree in Chemical and Biomolecular Engineering from The Hong Kong University of Science and Technology in 2019. His work experience involved the designs, feasibility studies, project management, operation and maintenance for landfill gas or biogas related utilisation projects and processing facilities.

\section{References}

[1] BBC Weather Centre (2014). Climate Change Methane. [online]. Available at: $<$ http://www.bbc. co.uk/climate/evidence/methane.shtml $>$. [Accessed on 27 March 2020].

[2] Engineering ToolBox (2003). Gases - Specific Gravities. [online]. Available at: <https://www. engineeringtoolbox.com/specific-gravitiesgases-d_334.html> . [Accessed on 27 March 2020].

[3] Environmental Proectuion Department (2020). Organic Resources Recovery Centre (ORRC). [online]. HKSAR Goverment. Available at: <https://www.epd. gov.hk/epd/english/environmentinhk/waste/prob solutions/WFdev_OWTF.html >. [Accessed on $2 \overline{7}$ March 2020].

[4] GB13611 (2018). Classification and basic characteristics of city gas. China.

[5] Hattwig M and Steen H (2004). Handbook of explosion prevention and protection. United States: Wiley.

[6] Li Y and Khanal S M (2016). Bioenergy: Principles and Applications. United States: Wiley. 
[7] Milbrandt GSA (2014). Renewable Hydrogen Potential from Biogas in the United States. National Renewable Energy Laboratory, United States.

[8] Rousseau R W (1987). Handbook of separation process technology. New York: Wiley Interscience.

[9] Towngas (2020). Gas Production. [online]. Available at: $<$ https://www.towngas.com/en/About-Us/HongKong-Gas-Business/Gas-Production>. [Accessed on 27 March 2020].

[10] Towngas (2020). Landfill Gas. [online]. Available at: $<$ https://www.towngas.com/en/Social-Responsibility/ Environmental-Protection/landfillgas $>$. [Accessed on 27 March 2020].

[11] Zabetakis M (1965). Flammability Characteristics of Combustible Gas and Vapors. Bureau of Mines: U.S. Department of the Interior. 